\title{
FUNDUS CHANGES IN PRE-ECLAMPSIA AND ECLAMPSIA- AN OBSERVATIONAL STUDY
}

Karupputhevar Senthil1, Sivasamy Subhashankari², Ganesan Vidhubala³, Manoharan Suhanya ${ }^{4}$, Pugaledndhi Priyadharsini 5 , Bohar Sugapriya ${ }^{6}$, Sanjayraut Ashwini ${ }^{7}$

${ }_{1}^{1}$ Associate Professor, Department of Ophthalmology, Madurai Medical College, Madurai.

${ }_{2}^{2}$ Assistant Professor, Department of Ophthalmology, Madurai Medical College, Madurai.

${ }^{3}$ Senior Resident, Department of Ophthalmology, Madurai Medical College, Madurai.

4Junior Resident, Department of Ophthalmology, Madurai Medical College, Madurai.

5Junior Resident, Department of Ophthalmology, Madurai Medical College, Madurai.

6 Junior Resident, Department of Ophthalmology, Madurai Medical College, Madurai.

7Junior Resident, Department of Ophthalmology, Madurai Medical College, Madurai.

\begin{tabular}{l} 
ABSTRACT \\
\hline BACKGROUND \\
Pre-eclampsia is reported to occur in around $25 \%$ of primigravida and $12 \%-15 \%$ of subsequent pregnancies. Ocular involvement \\
is common. Reversible cortical blindness and extraocular muscle palsy have also been documented in eclamptic patients. The \\
ocular vascular changes have been said to correlate with the severity of hypertension and this has been used as an indicator for \\
termination of pregnancy. \\
The aim of this study is to determine the retinal changes in pre-eclampsia and eclampsia, and its relationship with severity of \\
hypertension.
\end{tabular}

\section{MATERIALS AND METHODS}

An observational study was conducted over the period of 9 months at Department of Ophthalmology, Madurai Medical College among 199 patients, who fit into the diagnostic criteria of pre-eclampsia and eclampsia. After obtaining a detailed history, a thorough ocular examination was conducted with necessary blood investigations. All subjects were reviewed again at Ophthalmology Department two weeks after delivery.

\section{RESULTS}

The information collected regarding all the cases were recorded in a Master Chart. The study subjects were segregated into three major groups- Group 1: Mild Pre-eclampsia - BP > 140/90 mmHg with proteinuria > $300 \mathrm{mg} / \mathrm{mL}$; Group 2: Severe pre-eclampsia $\mathrm{BP}>160 / 110 \mathrm{mmHg}$ with proteinuria $>500 \mathrm{mg} / \mathrm{mL}$ associated with elevated renal parameters/ pulmonary oedema/ HELLP syndrome/ foetal compromise; and Group 3: Eclampsia- any unexplained seizures/ coma. The eclampsia group had more number of aged mothers, primigravida with generalised and pedal oedema and also proteinuria, whereas mothers with severe preeclampsia and mild pre-eclampsia were in the lower age group with or without pedal oedema and proteinuria, and the visual acuity was found to improve in all the three groups after delivery.

\section{CONCLUSION}

The frequency and severity of fundus changes more closely follow the severity of hypertension and also an associated early onset of pre-eclampsia by $24-28$ weeks of pregnancy. Most of the patients with grade 1 and grade 2 fundus changes had an uncomplicated mode of delivery with a good foetal outcome and fundus findings resolved after delivery.

\section{KEYWORDS}

Eclampsia, Pre-eclampsia, Hypertension, Pregnancy.

HOW TO CITE THIS ARTICLE: Senthil K, Subhashankari S, Vidhubala G, et al. Fundus changes in pre-eclampsia and eclampsia- an observational study. J. Evolution Med. Dent. Sci. 2018;7(03):291-293, DOI: 10.14260/jemds/2018/64

\section{BACKGROUND}

Pre-eclampsia is reported to occur in around $25 \%$ of primigravida and $12 \%-15 \%$ of subsequent pregnancies. Ocular involvement is common in $30 \%-100 \%$ of these patients like hypertensive retinopathy, exudative retinal detachment, vitreous haemorrhage, retinal haemorrhage, ischaemic optic neuropathy and hypertensive choroidopathy. 1

'Financial or Other Competing Interest': None.

Submission 15-11-2017, Peer Review 29-12-2017,

Acceptance 05-01-2018, Published 13-01-2018.

Corresponding Author:

Dr. Karupputhevar Senthil,

Associate Professor of Diabetology,

Eye Department of OP No. 50, Government Rajaji Hospital,

No. 1, Panagal Road, Madurai-625020, Tamilnadu.

E-mail: eyedeptgrh@gmail.com

DOI: $10.14260 /$ jemds $/ 2018 / 64$

\section{(c) $($ ) $\$$}

Reversible cortical blindness and extraocular muscle palsy have also been documented in eclamptic patients. The ocular vascular changes have been said to correlate with the severity of hypertension and this has been used as an indicator for termination of pregnancy.

\begin{abstract}
Aim
To determine the retinal changes in pre-eclampsia and eclampsia, and its relationship with severity of hypertension.
\end{abstract}

\section{MATERIALS AND METHODS}

An observational study was conducted over the period of 9 months at Department of Ophthalmology, Madurai Medical College among 199 patients who fit into the diagnostic criteria of pre-eclampsia and eclampsia ( $>20$ weeks of pregnancy, blood pressure $>140 / 90 \mathrm{mmHg}$ and Proteinuria). The formula used by our statistician to determine the sample size is $\left[\mathrm{Z}_{1-\alpha / 2^{2}} \mathrm{p}(1-\mathrm{p})\right] / \mathrm{d}^{2}$, where $\mathrm{Z}_{1-\alpha / 2}$ is the standard normal 
variate at $5 \%$ type I error $(\mathrm{p}<0.05)$, which is 1.96 . ' $\mathrm{P}$ ' is the expected proportion in population based on pilot study is $10 \%$ and ' $\mathrm{d}$ ' is the absolute error or precision is $5 \%$. The sample size was found to be 199 . Patients who had preexisting diabetes mellitus, hypertension, renal disease and ocular condition which makes fundus examination difficult were excluded from this study. After obtaining a detailed history a thorough ocular examination was conducted including visual acuity, fundus photograph, blood urea, serum creatinine, serum uric acid, complete haemogram and urine examinations for protein and sugar was done. All subjects were reviewed again at Ophthalmology Department two weeks after delivery. All the statistical analysis was done using statistical software IBM SPSS Ver. 21.0 (Armonk, NY).

\section{RESULTS}

The information collected regarding all the cases were recorded in a Master Chart. The study subjects were segregated into three major groups ${ }^{2,3}$ namely, Group 1: Mild pre-eclampsia - BP > 140/90 $\mathrm{mmHg}$ with proteinuria $>300$ $\mathrm{mg} / \mathrm{mL}$, Group 2: Severe pre-eclampsia - BP > 160/110
mmHg with proteinuria $>500 \mathrm{mg} / \mathrm{mL}$ associated with elevated renal parameters/ pulmonary oedema/ HELLP syndrome/ foetal compromise, and Group 3: Eclampsia- any unexplained seizures/ coma. The distribution of subjects into these three major groups and their mean, standard deviation and range is shown in Table 1 . The eclampsia group had more number of aged mothers, primigravida with generalised and pedal oedema and also proteinuria, whereas mothers with severe pre-eclampsia and mild pre-eclampsia were in the lower age group with or without pedal oedema and proteinuria, Table 2 . So, the ' $p$ ' value $<0.001$ by Fisher's exact test and Chi-square test respectively shows that presence of generalised or pedal oedema and proteinuria were statistically significant among the factors observed. ' $\mathrm{P}$ ' value $<0.05$ by Wilcoxon Signed rank test showed that the visual acuity was found to improve in all the three groups after delivery, Table 3. On comparing the severity of hypertension and fundus changes in Retinopathy before and after delivery, the 'p' value by Fisher's exact test was $<0.001$ and hence statistically significant, Table 4.

\begin{tabular}{|c|c|c|c|}
\hline Group & N & Mean (SD) & RANGE \\
\hline Mild pre-eclampsia & 95 & $22.49(4.15)$ & $16-35$ \\
\hline Severe pre-eclampsia & 80 & $22.91(4.41)$ & $16-35$ \\
\hline Eclampsia & 24 & $23.62(4.33)$ & $17-32$ \\
\hline Total Table 1. Descriptive Statistics for Age (Years) & $16-35$ \\
\hline \multicolumn{2}{|c}{} \\
\hline
\end{tabular}

\begin{tabular}{|c|c|c|c|c|c|c|}
\hline \multirow{2}{*}{\multicolumn{2}{|c|}{ Parameter }} & Mild Pre-Eclampsia & Severe Pre-Eclampsia & Eclampsia & Total & \multirow{2}{*}{$P$ value } \\
\hline & & $\mathrm{N}(\%)$ & $\mathrm{N}(\%)$ & $\mathrm{N}(\%)$ & $\mathrm{N}(\%)$ & \\
\hline \multirow{4}{*}{ Age group } & $<20$ yrs. & $35(50)$ & $30(42.86)$ & $5(7.14)$ & $70(100)$ & \multirow{4}{*}{$\begin{array}{c}0.618^{¥} \\
\text { (NS) }\end{array}$} \\
\hline & $21-25$ yrs. & $38(49.35)$ & $29(37.66)$ & $10(12.9)$ & $77(100)$ & \\
\hline & $26-30$ yrs. & $17(39.53)$ & $18(41.86)$ & $8(18.6)$ & $43(100)$ & \\
\hline & $>30$ yrs. & $5(55.56)$ & $3(33.33)$ & $1(11.11)$ & $9(100)$ & \\
\hline \multirow{3}{*}{ Gravida } & Primi & $60(48)$ & $52(41.6)$ & $13(10.4)$ & $125(100)$ & \multirow{3}{*}{$0.626^{€}(\mathrm{NS})$} \\
\hline & Multi & $35(47.3)$ & $28(37.84)$ & $11(14.86)$ & $74(100)$ & \\
\hline & Total & $95(47.74)$ & $80(40.2)$ & $24(12.06)$ & $199(100)$ & \\
\hline \multirow{2}{*}{ Pedal oedema } & Present & $6(100)$ & 0 & 0 & $6(100)$ & \multirow{2}{*}{$\begin{array}{c}0.052^{¥} \\
\text { (NS) }\end{array}$} \\
\hline & Absent & $89(46.11)$ & $80(41.45)$ & $24(12.44)$ & $193(100)$ & \\
\hline \multirow{2}{*}{ Generalised oedema } & Absent & $90(61.64)$ & $56(38.36)$ & 0 & $146(100)$ & \multirow{2}{*}{$\begin{array}{c}<0.001^{€} \\
(\mathrm{~S})\end{array}$} \\
\hline & Present & $5(9.43)$ & $24(45.28)$ & $24(45.28)$ & $53(100)$ & \\
\hline \multirow{4}{*}{ Proteinuria } & $1+$ & $4(9.52)$ & $33(78.57)$ & $5(11.9)$ & $42(100)$ & \multirow{4}{*}{$\begin{array}{c}<0.001^{¥} \\
\text { (S) }\end{array}$} \\
\hline & $2+$ & 0 & $3(13.64)$ & $19(86.36)$ & $22(100)$ & \\
\hline & Absent & $58(100)$ & 0 & 0 & $58(100)$ & \\
\hline & Trace & 33 (42.86) & $44(57.14)$ & 0 & 77 (100) & \\
\hline
\end{tabular}

$¥$ is Fisher’s exact test, € is Chi-square test.

\begin{tabular}{|c|c|c|c|c|}
\hline Group & Visual Acuity & Mean(SD) & Median(IQR) & P value \\
\hline \multirow{2}{*}{ Mild pre-eclampsia } & Before delivery & $0.1\{6 / 6\}(0.22)$ & $0\{6 / 6\}(0-0.18)$ & \multirow{2}{*}{0.025} \\
\hline & After delivery & $0.08\{6 / 6\}(0.19)$ & $0\{6 / 6\}(0-0.18)$ & \\
\hline \multirow{2}{*}{ Severe pre-eclampsia } & Before delivery & $0.18\{6 / 9\}(0.26)$ & $0\{6 / 6\}(0-0.3)$ & \multirow{2}{*}{0.0005} \\
\hline & After delivery & $0.14\{6 / 9\}(0.22)$ & $0\{6 / 6\}(0-0.18)$ & \\
\hline \multirow{2}{*}{ Eclampsia } & Before delivery & $0.29\{6 / 12\}(0.42)$ & $0.09\{6 / 6\}(0-0.3)$ & \multirow{2}{*}{0.0146} \\
\hline & After delivery & $0.23\{6 / 12\}(0.41)$ & $0\{6 / 6\}(0-0.18)$ & \\
\hline \multirow{2}{*}{ Total } & Before delivery & $0.15\{6 / 9\}(0.27)$ & $0\{6 / 6\}(0-0.18)$ & \multirow{2}{*}{$<0.001$} \\
\hline & After delivery & $0.13\{6 / 9\}(0.24)$ & $0\{6 / 6\}(0-0.18)$ & \\
\hline
\end{tabular}

$€$ is Wilcoxon Signed rank test. 


\begin{tabular}{|c|c|c|c|c|c|c|c|c|}
\hline \multirow{2}{*}{\multicolumn{2}{|c|}{ Group }} & \multicolumn{6}{|c|}{ Severity of Hypertension N (\%) } & \multirow{2}{*}{ P value $^{f}$} \\
\hline & & \multirow{2}{*}{$\frac{\mathbf{0}}{47(49.47)}$} & \multirow{2}{*}{$\frac{1}{36(37.89)}$} & \multirow{2}{*}{$\frac{\mathbf{2}}{12(12.63)}$} & \multirow{2}{*}{$\begin{array}{l}\mathbf{3} \\
0 \\
\end{array}$} & \multirow{2}{*}{$\begin{array}{l}4 \\
0\end{array}$} & \multirow{3}{*}{$\begin{array}{c}\text { Total } \\
95(100)\end{array}$} & \\
\hline Mild & Before delivery & & & & & & & \multirow{6}{*}{$<0.001$} \\
\hline pre-eclampsia & After delivery & $92(96.84)$ & $3(3.16)$ & 0 & 0 & 0 & & \\
\hline \multirow{2}{*}{$\begin{array}{c}\text { Severe } \\
\text { pre-eclampsia }\end{array}$} & Before delivery & $2(2.5)$ & $37(46.25)$ & $29(36.25)$ & $10(12.5)$ & $2(2.5)$ & \multirow{2}{*}{$\begin{array}{c}80 \\
(100)\end{array}$} & \\
\hline & After delivery & $73(91.25)$ & $5(6.25)$ & $2(2.5)$ & 0 & 0 & & \\
\hline \multirow{2}{*}{ Eclampsia } & Before delivery & 0 & $5(20.83)$ & $11(45.83)$ & $2(8.33)$ & $6(25)$ & \multirow{2}{*}{$\begin{array}{c}24 \\
(100)\end{array}$} & \\
\hline & After delivery & $2(8.33)$ & $16(66.67)$ & $6(25)$ & 0 & 0 & & \\
\hline \multirow{2}{*}{ Total } & Before delivery & $49(24.62)$ & $78(39.2)$ & $52(26.13)$ & $12(6.03)$ & $8(4.02)$ & \multirow{2}{*}{$\begin{array}{c}199 \\
(100)\end{array}$} & \\
\hline & After delivery & $167(91.25)$ & $24(12.06)$ & $8(4.02)$ & 0 & 0 & & \\
\hline \multicolumn{9}{|c|}{ Table 4. Comparison of Retinal Changes with Severity of Hypertension After Delivery } \\
\hline
\end{tabular}

F- Fisher's exact test.

\section{DISCUSSION}

The retinal and choroidal circulations are affected in preeclampsia and eclampsia with retinopathy similar to hypertensive retinopathy. Serous retinal detachments, retinal pigment epithelial lesions, occlusions of the vessels and cortical blindness are also seen here.4,5 Retinal arteriolar narrowing (focus or generalised) is the most common finding in pre-eclampsia. This is due to vasospasm of the central retinal artery, which usually resolves in the postpartum period due to normalisation of blood flow. ${ }^{6}$ Other retinal changes include hard exudates, flame-shaped haemorrhages, dot and blot haemorrhages, cotton wool spots and retinal oedema.

Retinal findings were graded as per American Ophthalmological Society's classification of retinal changes in pre-eclampsia and eclampsia: Grade 0: Normal fundus; Grade 1 and 2: Characterised by slight or moderate degrees of reflex strip arterial-venous narrowing and spasm- the stage of angiospasm; Grade 3: The above with oedema, haemorrhage and exudates- pre-eclampsia; and Grade 4: Papilloedema. Choroidal dysfunction clinically manifests as yellow retinal pigment epithelial lesions and retinal detachment (Serous, Bullous, Bilateral). All these usually resolved in the postpartum period.

In one study done by Tadin L et al 7 in 40 women with preeclampsia, there was a statistically significant correlation between the degree of hypertensive retinopathy and patient's age, APGAR score, tropism, proteinuria, blood pressure and oedema. He concluded that the degree of retinopathy was directly proportional to the severity of pre-eclampsia. In another study by Sagili Chandrasekhara Reddy et al ${ }^{8}$ done in 78 PIH patients, he found Grade 1 and Grade 2 hypertensive retinopathies in $59 \%$ of the subjects and they were significantly associated with blood pressure, proteinuria and severity of the disease and concluded that fundus examination helps in assessing the severity of PIH.

Strict control of blood pressure should be initiated and all meticulous precautions to prevent eclampsia should be taken. Usually, medical management is aimed at correction of the abnormal derangements in the maternal metabolism and correction imbalances in the electrolyte levels. If preeclampsia resists to medical management, immediate delivery with labour induction and caesarean section is advised. Treatment of eclampsia includes control of convulsions, hypoxia and acidosis correction, control of blood pressure and planning for delivery after the control of convulsions. This retinopathy also reverts to normal after delivery with complete restoration of vision frequently.

\section{CONCLUSION}

The frequency and severity of fundus changes more closely follow the severity of hypertension and also an associated early onset of pre-eclampsia by $24-28$ weeks of pregnancy. This shows that increased blood pressure, when it is persistent for more than 8 - 10 weeks results in an increased severity of retinopathy. Most of the patients with Grade 1 and Grade 2 fundus changes had an uncomplicated mode of delivery with a good foetal outcome and fundus findings resolved after delivery.

\section{REFERENCES}

[1] Richard RO. Pregnancy induced hypertension (preeclampsia-ecclampsia) In: Schachat AP, Murphy RB. (eds). Retina. $2^{\text {nd }}$ edn. St Louis: Mosby, 1994:140512.

[2] Nalliah S, Abdullah AR. Eclampsia in Kelantan. Med J Malaysia 1990;45(1):49-56.

[3] Noraihan MN, Sharda P, Jammal AB. Report of 50 cases of eclampsia. J Obstet Gynaecol Res 2005;31(4):302-9.

[4] Nalliah S, Thavarashah AS. Transient blindness in pregnancy induced hypertension. Int J Gynaecol Obstet 1989;29(3):249-51.

[5] Achanna S, Monga D, Sivagnanam. Transient blindness in pregnancy induced hypertension. Asia Oceania J Obstet Gynaecol 1994;20(1):49-52.

[6] Rasdi AR, Nik-Ahmad-Zuki NL, Bakiah S, et al. Hypertensive retinopathy and visual outcome in hypertensive disorders in pregnancy. Med J Malaysia 2011;66(1):42-7.

[7] Tadin I, Bojić L, Mimica M, et al. Hypertensive retinopathy and pre-eclampsia. Coll Antropol 2001;25 Suppl:77-81.

[8] Reddy SC, Nalliah S, George SR, et al. Fundus changes in pregnancy induced hypertension. Int J Ophthalmol 2012;5(6):694-7. 